Canadian Studies in Population, Vol. 28(1), 2001, pp. 89-110

\title{
Narrowing Sex Differences in Life Expectancy: Regional Variations, 1971-1991*
}

\author{
Frank Trovato \\ N.M. Lalu \\ Department of Sociology and \\ Population Research Laboratory \\ University of Alberta \\ Edmonton, Alberta, Canada
}

\begin{abstract}
A number of industrialized nations have recently experienced some degrees of constriction in their long-standing sex differentials in life expectancy at birth. In this study we examine this phenomenon in the context of Canada's regions between 1971 and 1991: Atlantic (Newfoundland, Nova Scotia, New Brunswick, Prince Edward Island); Quebec, Ontario, and the West (Manitoba, Saskatchewan, Alberta, British Columbia, Yukon and Northwest Territories). Decomposition analysis based on multiple decrement life tables is applied to address three questions: (1) Are there regional differentials in the degree of narrowing in the sex gap in life expectancy? (2) What is the relative contribution of major causes of death to observed sex differences in average length of life within and across regions? (3) How do the contributions of cause-of-death components vary across regions to either widen or narrow the sex gap in survival? It is shown that the magnitude of the sex gap is not uniform across the regions, though the differences are not large. The most important contributors to a narrowing of the sex gap in life expectancy are heart disease and external types of mortality (i.e., accidents, violence, and suicide), followed by lung cancer and other types of chronic conditions. In substantive terms these results indicate that over time men have been making sufficient gains in these causes of death as to narrow some of the gender gap in overall survival. Regions show similarity in these effects.
\end{abstract}

Keywords: $\quad$ sex mortality differential; life expectancy, causes of death; life table decomposition, region. 


\section{Résumé}

Certains pays industrialisés viennent de vivre quelques constrictions dans la différentielle sexuelle de l'espérance de vie à la naissance. Dans cette étude, nous examinons ce phénomène dans le contexte des régions canadiennes entre 1971 et 1991 : région atlantique (Terre-Neuve, Nouvelle-Écosse, NouveauBrunswick, île du Prince-Édouard) ; le Québec, l'Ontario et l'Ouest (Manitoba, Saskatchewan, Alberta, Colombie-Britannique, Yukon et les Territoires du Nord-Ouest). L'analyse de décomposition basée sur des tables de survie et d'extinction multiples sert à répondre à trois questions : 1) Existe-t-il des écarts régionaux dans le degré de réduction de l'écart de l'espérance de vie entre les sexes ? 2) Quelle est la contribution relative des principales causes de décès avec différences observées entre les sexes dans la durée de vie moyenne dans les différentes régions ? 3) De quelle façon est-ce que les contributions des éléments de causes de décès varient selon les régions pour élargir ou réduire l'écart de survie entre les sexes ? Il appert que l'ampleur de l'écart entre les sexes n'est pas uniforme dans les régions, bien que les différences ne soient pas grandes. Les principaux éléments de contribution à la réduction de l'écart dans l'espérance de vie entre les sexes sont les maladies cardiaques et les facteurs externes de mortalité (p. ex. les accidents, la violence et le suicide), suivi du cancer du poumon et d'autres types de troubles chroniques. Ces résultats indiquent qu'au fil du temps, les hommes ont fait suffisamment de progrès dans ces causes de décès pour faire réduire l'écart de la survie générale entre les sexes. Les régions indiquent une similarité de ces effets.

Mots clés : différentielle sexuelle de mortalité, espérance de vie, cause de décès, décomposition de la table de survie, région

\section{Introduction}

Historically, industrialized societies have followed a pattern of widening sex differences in life expectancy, favoring females by anywhere from two to seven years, depending on the time period and the country (Acsadi and Nemeskeri, 1970; Lopez, 1983; 1993; Preston, 1976; Stolnitz, 1956; Waldron, 1993). Notwithstanding the continuation of survival gains by both genders, some societies have been experiencing varying degrees of constriction in their sex differentials in life expectancy at birth (Trovato and Lalu, 1995; 1996a, 1996b, 1997, 1998). Though not yet widespread to all industrialized nations, this represents an emerging feature of the fourth stage of epidemiological transition (Omran, 1971; Olshansky and Ault, 1986; Rogers and Hackenberg, 1987). 
Narrowing Sex Differences in Life Expectancy

Regional Variations, 1971-1991

\section{Regional Variations}

Historically, Canada's regions have shared significant differences along social, economic, sociopolitical and demographic dimensions (Innis, 1930; Goyder, 1993; Hiller, 1986). Quebec and Ontario are the two most populous areas of the nation. In 1991 these two provinces accounted for 62 per cent of the total Canadian populations (Ontario 37\%; Quebec 25.3\%). The Atlantic region as a whole comprises a much smaller percentage of the population, 8.5 per cent. The remaining 30 per cent live in Manitoba, Alberta, British Columbia, Yukon and Northwest Territories (McVey and Kalbach, 1995:46). The Atlantic region, next to the two Territories (Northwest Territories now subdivided into Nunavut and the rest of NWT), is the poorest area of the country (Hiller, 1986).

One indicator of this reality is its region's historical experience of net migration losses (George, 1971; Stone, 1971). Quebec, a predominantly French speaking population, is comprised of the descendants of the first settlers from France in 1608 (the initial voyage by Champlain included only 30 persons) (Henripin, 1954), plus a growing heterogeneous immigrant population (Hiller, 1986). Although this society has undergone significant social and economic change, it continues to represent the core of francophone Canada. It views itself politically and culturally different from the rest of Canada, its identity shaped by its French roots. ${ }^{1}$ Given its strong English loyalist roots, Ontario - with the exception of polyethnic Toronto - is perhaps the epitome of anglophone Canada. Historically, it has represented the heartland of industry in the country. And has enjoyed a long-standing advantage in net migration gains in relation to other provinces. On an annual basis, this province also gains an overwhelming majority of new immigrants to Canada (McVey and Kalbach, 1995). ${ }^{2}$ The Western provinces of Manitoba, Saskatchewan, Alberta and British Columbia, comprise a diverse set of social geographies. The former three provinces were formed by the opening of the west campaign during the formative years of the nation during the mid 1800s. Early in their histories, these provinces attracted large migratory flows from Eastern and Northwestern Europe. These provinces are characterized by agriculture, and resource economies, including oil, gas and forestry. Over the decades of the post-War years, they have tended to experience periods of economic booms and busts, dictated by fluctuation in the market prices of these resources. Thus, internal migratory flows to these provinces have been largely dictated by economic fluctuations in these industries. British Columbia, the westernmost province, until recently was the fastest growing province in Canada in terms of its economy and also net migration. In the late 1990s, Alberta led the rest of the country in economic growth; it therefore enjoyed large net migration gains (Belanger, 1999).

In Canada, geographic variations in life expectancy have been noted since the beginning of the Vital Statistics System in 1921. As indicated in Table 1, through the Post-War years, provincial differences in this measure have been following a convergent trend. ${ }^{3}$ Period-specific coefficients of variation have 
reduced considerably over time, particularly since the early 1950s. Gender differences in the average length of life across the provinces have not been uniform. For instance, taking the female minus the male expectancy, during the early 1950s, British Columbia and Ontario showed the largest sex gaps, each in the vicinity of 5 years in favor of women. During the two most recent periods, Saskatchewan and Prince Edward Island had the widest gender based disparities in 1985-87; and Prince Edward Island and Quebec in 1990-92. As noted here and previously by several authors (Trovato and Lalu, 1995, 1998; Nault, 1997; Manuel and Hockin, 2000) the sex differential in Canada peaked during the 1970s at about 7 years in favor of women, and has recently begun to constrict. Table 1 indicates this general pattern for the Canadian provinces.

\section{Study Objectives}

Previous studies concerning this new trend have looked at the country as the unit of analysis. In the present research we examine cause-of-death contributions to the sex gap in life expectancy across Canadian regions over the two decades between 1971 and 1991. Our expectation is that the Canadian regions will conform to a similar type of trend in the sex differential in life expectancy that has been observed recently in a number of advanced societies, though it is unlikely that the differentials would be uniform across the regions. We apply decomposition methods based on multiple decrement life tables to examine three questions: (1) Are there regional differentials in the degree of narrowing in the sex gap in life expectancy? (2) What is the relative contribution of cause-ofdeath components to observed sex differences in average length of life across regions? (3) How do contributions of cause-of-death components vary across regions to either widen or narrow the observed sex gaps in life expectation between 1971 and 1991 ?

\section{Data and Methods of Analysis}

The data for this study were obtained from Statistics Canada's Health Division as a special tabulation consisting of cause-specific deaths by age, sex by province for 1971, 1981 and 1991. Corresponding census populations for these time points were also obtained from Statistics Canada. We have combined causes of death into six cause components, representing important sources of mortality variation in advanced societies: Heart Disease (C1); Cancers excluding that of the lung; (C2) Lung Cancer (C3); Other Chronic Diseases (C4); External Causes (C5); and Residual Causes of Death (C6). The first part of the statistical analysis involves the application of a decomposition formula developed by Das Gupta (1993) to decompose period-specific sex gaps in life expectancy at birth into the cause-of-death components. Secondly, we analyze the temporal change in cause contributions to the temporal change in the sex differences in life expectancy. Decomposition method is based on multiple decrement life table 
Narrowing Sex Differences in Life Expectancy

Regional Variations, 1971-1991

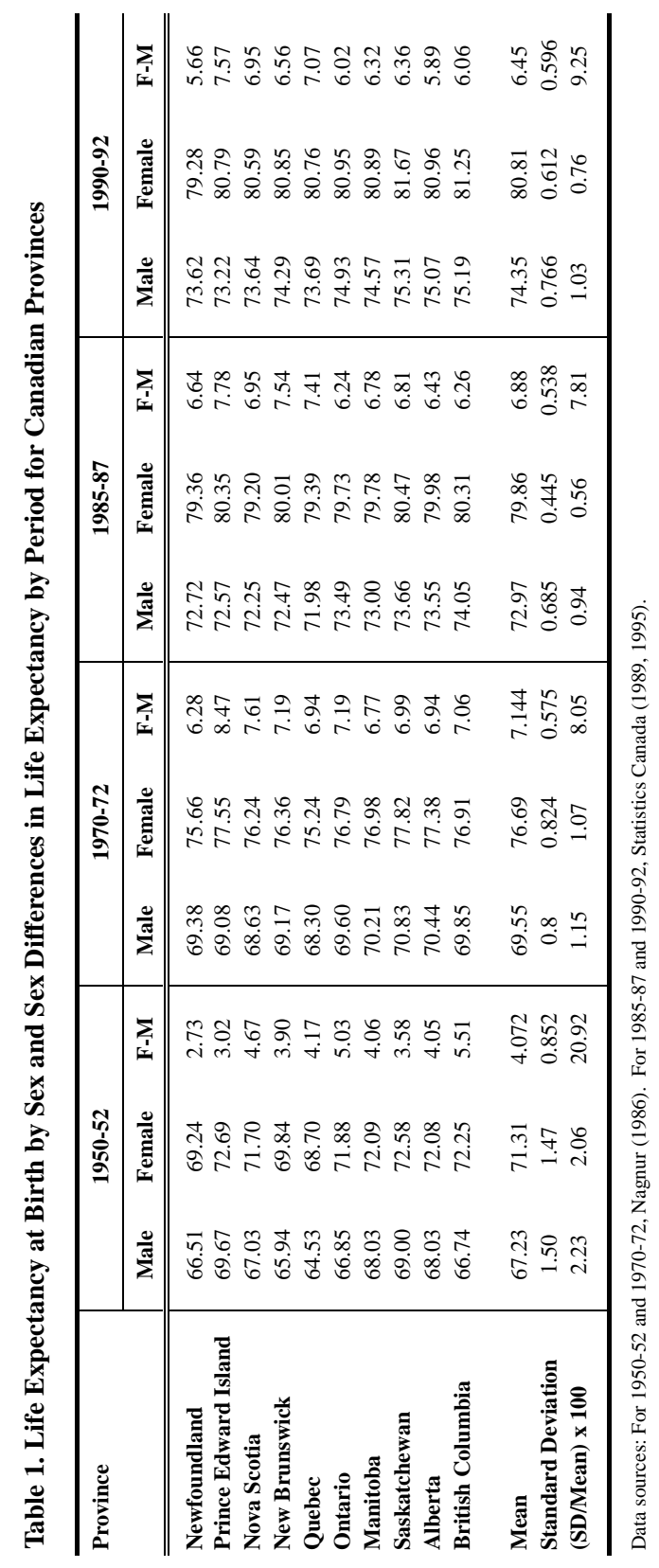


information. We had to compute gender-specific multiple decrement life tables from corresponding age-sex-cause-specific death rates for each region. Multiple decrement tables derive life table functions on the assumption that causes of death are independent and compete simultaneously in claiming lives. We have described this methodology in greater detail elsewhere (see Trovato and Lalu, 1995, 1996b, 1997, 1998). As the decompositions are based on life table data, results are net of age compositional differences. For any time period in the analysis, decomposition components with positive values would denote the sex mortality differential for that cause of death serves to increase the female advantage in life expectancy over males. On the other hand, a negative value would imply the opposite interpretation---that the sex differential in mortality for that particular cause serves to narrow the female advantage in life expectation. The magnitudes of component contributions are expressed in both relative (percentages) and absolute terms (actual years of life expectancy).

To elaborate on the second aspect of our decomposition analysis, the procedure involves taking the change in contribution between two points in time, of a given cause component, to the change in the observed sex gap in life expectancy. Here, our focus is on decomposing the absolute changes (in years of life expectancy or fractions thereof) in cause of death contributions, first between 1971 and 1981, and then between 1981 and 1991. In this type of analysis, a positive sign associated with a given cause component would indicate that the net effect of temporal change in the sex gap in death rates due to that cause of death acts to expand the sex gap in life expectancy in favor of females. A negative sign would denote the opposite effect (to reduce the female advantage). ${ }^{4}$

The provinces and territories are combined into four regions, as follows: (1) Atlantic (Newfoundland, Nova Scotia, New Brunswick, Prince Edward Island), (2) Quebec; (3) Ontario, (4) West (Manitoba, Saskatchewan, Alberta, British Columbia, Yukon and Northwest Territories). It would have been desirable to execute the analysis separately for each of the ten provinces and two territories. ${ }^{5}$ However this approach would have produced an inordinate number of empty cells in the multidimensional cross-tabulation of deaths and corresponding populations by gender, cause of death, age, and province, thus severely limiting the use of life table based decompositions. Unfortunately, we could not gain access to more recent mortality and population data for 1996; extension of the analysis to more recent periods could be undertaken in due course.

\section{Results}

It should be mentioned that the life expectancy we report in our statistical Tables, though very close, are not identical to those shown in Table 1 taken from official publications. This difference is largely attributable to differences in life table methodologies. Moreover, the expectancies in Table 1 for the two most 
recent periods are from single years of age life tables, while those based on computations in the present study are based on abridged life tables. Table 2 displays male and female life expectancies at birth by region and time period, plus the corresponding decompositions of the sex differences. As shown in the table, the largest sex gap in 1971 is evident in Ontario (7.338) and the Atlantic (7.321) regions. In 1981, the widest difference was in the Atlantic location (6.962). In 1991 it was Quebec that showed the largest differential (6.338). Judging from the declining magnitude of the differences in life expectancies across time and region in Table 2, one may conclude that the long-standing female advantage in overall life expectancy has been narrowing across the Canadian regions; and that the constrictions have intensified between 1981 and 1991. This pattern of change is consistent with earlier observations based on Canada as a whole, and other industrialized societies (Trovato and Lalu, 1995, 1996a, 1996b, 1997, 1998).

The relevance of cause-of- death components to explaining period-specific sex differences in life expectancy can be assessed with the information contained in Table 2. Sex differences in heart disease mortality explain anywhere from between 29 and almost 45 percent of the sex differential in life expectancy. The degree of this component's contribution varies by region and time period. For instance, in Ontario during 1971, this cause of death accounted for 44 percent of the sex gap in life expectancy, while in the West region this accounted for 38 percent. In substantive terms, this means that roughly between 30 and 45 per cent of the sex difference in longevity can be attributed to men's greater relative risk of heart disease mortality. This effect varies by region, suggesting the existence of a geographic factor in this phenomenon. Further investigation is required to explore this hypothesis in greater detail.

The next largest cause contribution to the female-male gap is sex differences in external causes of death---i.e. suicide, homicide, accidents and violence combined. The range of contribution is between 15 and 29 percent. Residual causes of death differences explain between 17 and 26 percent of the sex gap. Lung cancer is a significant factor, accounting for between 8 and 16 percent of the sex difference in life expectation. Other cancers and other chronic diseases contribute a relatively small proportion of the sex gap. Regional differences in cause-specific contributions to sex differences in life expectancy within each time period are displayed in Table 1. The graphs demonstrate the relative importance of each of the six cause components within each time period and region. It is quite clear that heart disease (Cause 1) and External conditions (Cause 5) are the most important determinants of the sex gap in life expectancy. The contribution of lung cancer seems to have risen across time in virtually all regions, except for the West and Ontario, where there is a small decline between 1981 and 1991. The same can be said in connection with "Other cancers" (other than lung), where there is noticeable rise over time, particularly during the interval 1981-1991. 
Table 2

Decomposition of Sex Difference in Life Expectancy by Region and Period for Canada, 1971, 1981 and 1991

\begin{tabular}{|c|c|c|c|c|c|c|}
\hline \multirow[b]{2}{*}{ Atlantic Region } & \multicolumn{2}{|c|}{1971} & \multicolumn{2}{|c|}{1981} & \multicolumn{2}{|c|}{1991} \\
\hline & e0 & & e0 & & e0 & \\
\hline Females & 76.257 & & 77.734 & & 79.186 & \\
\hline Males & 68.935 & & 70.772 & & 73.287 & \\
\hline Difference F-M & 7.321 & & 6.962 & & 5.899 & \\
\hline \multicolumn{7}{|l|}{ Decomposition } \\
\hline Cause & Absolute & $\%$ & Absolute & $\%$ & Absolute & $\%$ \\
\hline 1 & 3.092 & 42.237 & 2.562 & 36.805 & 1.902 & 32.236 \\
\hline 2 & 0.033 & 0.444 & 0.221 & 3.175 & 0.424 & 7.188 \\
\hline 3 & 0.603 & 8.23 & 0.801 & 11.512 & 0.786 & 13.317 \\
\hline 4 & 0.32 & 4.376 & 0.346 & 4.974 & 0.3 & 5.09 \\
\hline 5 & 1.871 & 25.559 & 1.684 & 24.194 & 1.251 & 21.212 \\
\hline 6 & 1.402 & 19.153 & 1.347 & 19.341 & 1.236 & 20.957 \\
\hline Total & 7.321 & 100.00 & 6.962 & 100.00 & 5.899 & 100.00 \\
\hline Quebec & e0 & & e0 & & e0 & \\
\hline Females & 75.573 & & 77.608 & & 79.365 & \\
\hline Males & 68.575 & & 70.717 & & 73.027 & \\
\hline Difference F-M & 6.998 & & 6.891 & & 6.338 & \\
\hline \multicolumn{7}{|l|}{ Decomposition } \\
\hline Cause & Absolute & $\%$ & Absolute & $\%$ & Absolute & $\%$ \\
\hline 1 & 2.792 & 39.902 & 2.498 & 36.255 & 1.839 & 29.018 \\
\hline 2 & 0.17 & 2.422 & 0.369 & 5.359 & 0.502 & 7.928 \\
\hline 3 & 0.727 & 10.394 & 0.98 & 14.223 & 1.028 & 16.222 \\
\hline 4 & 0.413 & 5.898 & 0.421 & 6.111 & 0.398 & 6.281 \\
\hline 5 & 1.666 & 23.813 & 1.442 & 20.922 & 1.262 & 19.905 \\
\hline 6 & 1.23 & 17.57 & 1.18 & 17.132 & 1.309 & 20.647 \\
\hline Total & 6.998 & 100.00 & 6.891 & 100.00 & 6.338 & 100.00 \\
\hline Ontario & e0 & & e0 & & e0 & \\
\hline Females & 76.848 & & 77.734 & & 79.4 & \\
\hline Males & 69.51 & & 71.724 & & 74.348 & \\
\hline Difference F-M & 7.338 & & 6.011 & & 5.052 & \\
\hline \multicolumn{7}{|l|}{ Decomposition } \\
\hline Cause & Absolute & $\%$ & Absolute & $\%$ & Absolute & $\%$ \\
\hline 1 & 3.248 & 44.261 & 2.48 & 41.261 & 1.639 & 32.449 \\
\hline 2 & 0.143 & 1.943 & 0.187 & 3.115 & 0.355 & 7.029 \\
\hline 3 & 0.697 & 9.498 & 0.722 & 12.013 & 0.581 & 11.495 \\
\hline 4 & 0.49 & 6.682 & 0.403 & 6.711 & 0.346 & 6.849 \\
\hline 5 & 1.407 & 19.177 & 1.12 & 18.642 & 0.806 & 15.96 \\
\hline 6 & 1.353 & 18.44 & 1.097 & 18.258 & 1.325 & 26.217 \\
\hline Total & 7.338 & 100.00 & 6.011 & 100.00 & 5.052 & 100.00 \\
\hline West* & e0 & & e0 & & e0 & \\
\hline Females & 77.272 & & 77.785 & & 79.766 & \\
\hline Males & 70.08 & & 71.492 & & 74.46 & \\
\hline Difference F-M & 7.192 & & 6.293 & & 5.306 & \\
\hline \multicolumn{7}{|l|}{ Decomposition } \\
\hline Cause & Absolute & $\%$ & Absolute & $\%$ & Absolute & $\%$ \\
\hline 1 & 2.721 & 37.83 & 2.252 & 35.778 & 1.698 & 31.996 \\
\hline 2 & 0.096 & 1.341 & 0.204 & 3.243 & 0.343 & 6.457 \\
\hline 3 & 0.635 & 8.83 & 0.615 & 9.777 & 0.497 & 9.361 \\
\hline 4 & 0.287 & 3.989 & 0.317 & 5.032 & 0.284 & 5.359 \\
\hline 5 & 2.029 & 28.207 & 1.81 & 28.762 & 1.361 & 25.645 \\
\hline 6 & 1.424 & 19.803 & 1.096 & 17.408 & 1.124 & 21.182 \\
\hline Total & 7.192 & 100.00 & 6.293 & 100.00 & 5.306 & 100.00 \\
\hline
\end{tabular}

Note: In this and subsequent Tables and Figures, Cause of Death is defines as: $1=$ Heart disease

2 = Cancers excluding that of the Lung; $3=$ Lung cancer; $4=$ Other chronic; 5 = External; $6=$ Residual .

* In this and subsequent tables, West region includes Yukon and Northwest Territories. 
Figure 1

Contribution of Causes of Death to Sex Difference in Life Expectancy By Period and Region, Canada: 1971, 1981 and 1991
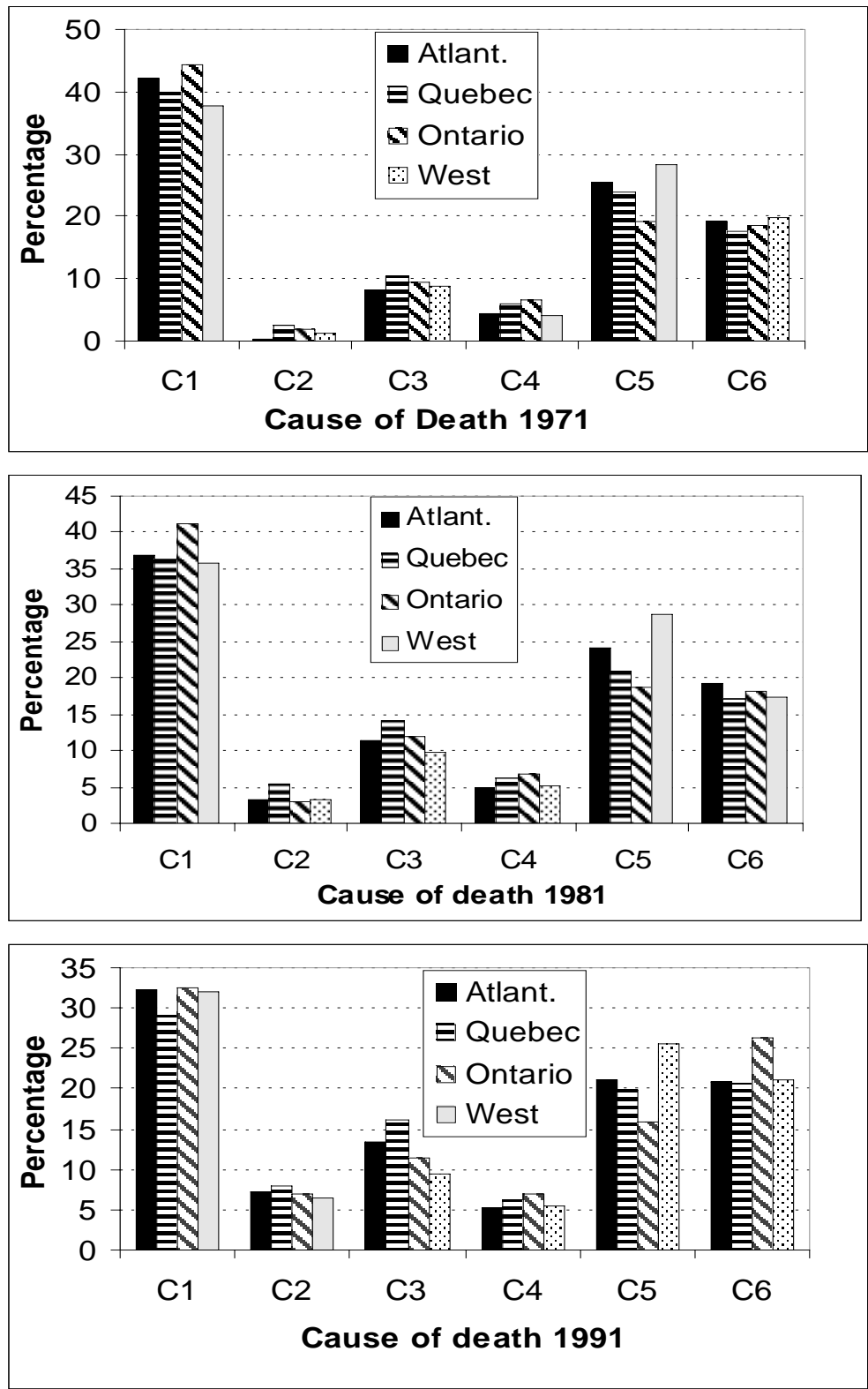

Note: $\mathrm{C} 1=$ Heart Disease; $\mathrm{C} 2=$ Cancer excluding that of the lung;

C3 = Lung Cancer; C4 = Other Chronic; C5 = External; C6 = Residual Causes 
Figure 1 shows that Ontario has led other regions with respect to Heart disease contribution to the sex differential in life expectancy. By 1991, Quebec had emerged as the region with the lowest contribution of Heart disease to the difference in life expectancy between the sexes. Moving on to External causes, the pattern of differentials by region has not really changed much over the three time points. The West region accounts for a larger contribution, followed by the Atlantic region. On the other hand, Ontario has the lowest contribution to the sex gap, and the Atlantic locality the largest. In substantive terms these differences suggest that much of the observed sex difference in life expectancy across Canadian regions is due to the combined contributions of sex differences in heart disease and external conditions. In other words, it is the excess mortality of males from these causes of death that contribute most to the sex gap in life expectation in favor of women. The next most important causes are "residual" and Lung cancer. The regional variations in the former cause are minimal in 1971 and 1981, but during 1991 Ontario shows a larger contribution than the other three regions. In the case of Lung cancer, Quebec leads in terms of contribution to the sex difference in survival. This is true across all three periods. This region also shows a dominance in connection with "Other types of Cancers" (Cause 2). Ontario on the other hand, contributes most with respect to "Other chronic conditions."

\section{Temporal Change in Components Contribution}

Table 3 displays absolute changes in the sex differential in life expectation (in terms of years of life or fraction thereof) between two successive periods: 19711981, and 1981-1991. The table also shows corresponding decompositions relating to change in cause component contributions to the temporal change in the sex gap in life expectancy. A narrowing of the sex differential in life expectancy over time is evident across all four regions. The situation in Ontario suggests that between 1981 and 1991 the degree of narrowing slowed down somewhat. It is not clear why the amount of narrowing reduced in Ontario, from -1.327 between 1971 and 1981, to just under one year between 1981 and 1991 . A detailed analysis of male and female death rates and their changes is required to better ascertain the reasons behind this result. In appendixes A and B we provide a table of age-standardized death rates by sex, cause, period and region. As indicated in these tables, the Ontario situation is explained by a widening of the male-female mortality differential due to "other cancers;" that is, all cancers other than that of lung. In effect, the male rates remained stable between 1981 and 1991, while those of females declined, thus contributing to a widening of the life expectancy differential. On the other hand, all of the other male-female rate contrasts show a declining gap between men and women.

Generally speaking, males have higher death rates than females from virtually every major causes of death. The decomposition tables in this study suggest that the net constriction of the sex gap in life expectancy across the four regions have 
Narrowing Sex Differences in Life Expectancy Regional Variations, 1971-1991

Table 3

Absolute Change in the Sex Difference in Life Expectancy and Decomposition by Cause of Death for Canadian Regions, 1971-1981 and 1981-1991

\begin{tabular}{|c|c|c|c|}
\hline Atlantic Region & & Change: 1981-1971 & Change: 1991-1981 \\
\hline Females & & 1.477 & 1.452 \\
\hline Males & & 1.837 & 2.515 \\
\hline Difference F-M & & -0.359 & -1.063 \\
\hline \multicolumn{4}{|l|}{ Decomposition } \\
\hline \multirow[t]{7}{*}{ Cause 1} & & -0.530 & -0.660 \\
\hline & 2 & 0.188 & 0.203 \\
\hline & 3 & 0.198 & -0.015 \\
\hline & 4 & 0.026 & -0.046 \\
\hline & 5 & -0.187 & -0.433 \\
\hline & 6 & -0.055 & -0.111 \\
\hline & Total & -0.359 & -1.063 \\
\hline \multicolumn{4}{|l|}{ Quebec } \\
\hline Females & & 2.035 & 1.757 \\
\hline Males & & 2.142 & 2.310 \\
\hline Difference F-M & & -0.107 & -0.553 \\
\hline \multicolumn{4}{|l|}{ Decomposition } \\
\hline Cause 1 & & -0.294 & -0.659 \\
\hline & 2 & 0.199 & 0.133 \\
\hline & 3 & 0.253 & 0.048 \\
\hline & 4 & 0.008 & -0.023 \\
\hline & 5 & -0.224 & -0.180 \\
\hline & 6 & -0.050 & 0.129 \\
\hline & Total & -0.107 & -0.553 \\
\hline \multicolumn{4}{|l|}{ Ontario } \\
\hline Females & & 0.886 & 1.666 \\
\hline Males & & 2.214 & 2.624 \\
\hline Difference F-M & & -1.327 & -0.959 \\
\hline \multicolumn{4}{|l|}{ Decomposition } \\
\hline Cause 1 & & -0.768 & -0.841 \\
\hline & 2 & 0.044 & 0.168 \\
\hline & 3 & 0.025 & -0.141 \\
\hline & 4 & -0.087 & -0.057 \\
\hline & 5 & -0.287 & -0.314 \\
\hline & 6 & -0.256 & 0.228 \\
\hline & Total & -1.327 & -0.959 \\
\hline \multicolumn{4}{|l|}{ West } \\
\hline Females & & 0.513 & 1.981 \\
\hline Males & & 1.412 & 2.968 \\
\hline Difference F-M & & -0.899 & -0.987 \\
\hline \multicolumn{4}{|l|}{ Decomposition } \\
\hline Cause 1 & & -0.469 & -0.554 \\
\hline & 2 & 0.108 & 0.139 \\
\hline & 3 & -0.020 & -0.118 \\
\hline & 4 & 0.030 & -0.033 \\
\hline & 5 & -0.219 & -0.449 \\
\hline & 6 & -0.328 & 0.028 \\
\hline & Total & -0.899 & -0.987 \\
\hline
\end{tabular}

Note: The change is measured in terms of years of life expectancy or fraction thereof.

Cause of Death is defines as $1=$ Heart disease; $2=$ Cancers excluding that of the lung;

$3=$ Lung cancer; $4=$ Other chronic; $5=$ External; $6=$ Residual. 
been largely accounted by a combination of steep rises in female mortality over time---especially lung cancer, in conjunction with some mortality improvements in the case of males. The age-standardized death rates in Appendixes A and B confirm this. While both genders have been enjoying mortality improvements, over time male gains have been somewhat greater across all four regions.

The proportionate contribution of a given cause to the sex difference in life expectancy can be affected by change in any of the other causes in the analysis. To overcome this problem, it was decided to examine the absolute change in component contribution by region for the successive periods of 1971-81 and 1981-91. This information is given in Figure 2.

A number of important points can be made based on this information. First, the dominance of heart disease is more clearly evident (something already indicated). Over the two time intervals, the contribution of this cause component has intensified toward narrowing the life expectancy gap between the sexes. This phenomenon is most pronounced in Quebec and least intense in Ontario. The range of contribution of heart disease component is between 0.3 of a year (Quebec between 1971 and 1981) and 0.8 of a year in Ontario between 1981 and 1991. It would appear that a major change has taken place in Quebec over the 1970s and 1980s with regard to male and female differences in mortality from heart disease, with male improvements being somewhat larger than those of females (see Appendixes A and B). This phenomenon deserves more careful study in subsequent research.

As already identified in the previous tables and figures, "external" types of mortality (i.e. suicide, homicide, accidents and violence combined) account for the next most important contribution to the constriction of life expectancy difference between the sexes. The Atlantic region and the West have experienced the largest narrowing due to this cause component. In both cases, the contribution dropped from approximately 0.2 of a year in the first time interval, to close to 0.5 of a year in the latter period. The narrowing effect in Ontario has been less dramatic. In Quebec, the contribution of "external" mortality weakened over time, though from the information in the Appendixes, it is clear that both sexes have enjoyed improvements over time in this cause of death.

Concerning Lung cancer, this component has followed a pattern of contribution to widen the sex difference in life expectancy during the 1970s, particularly in the Atlantic region, Quebec and Ontario. In the West it accounted for a narrowing of the gap beginning in the 1970s and continuing into the 1980s. The Quebec case is interesting, due to the still positive (though declining) effect of this cause component over time. In fact, during the 1981-91 interval, Quebec was the only region where the effect of this cause of death is positive due to male mortality rates from this disease rising faster than those of females. Notwithstanding this fact, it is also worth noting that although positive, the 
Figure 2

Change in Contribution of Cause Components to Change in Sex Difference in Life Expectancy by Region, Canada: 1971-1981 and 1981-1991
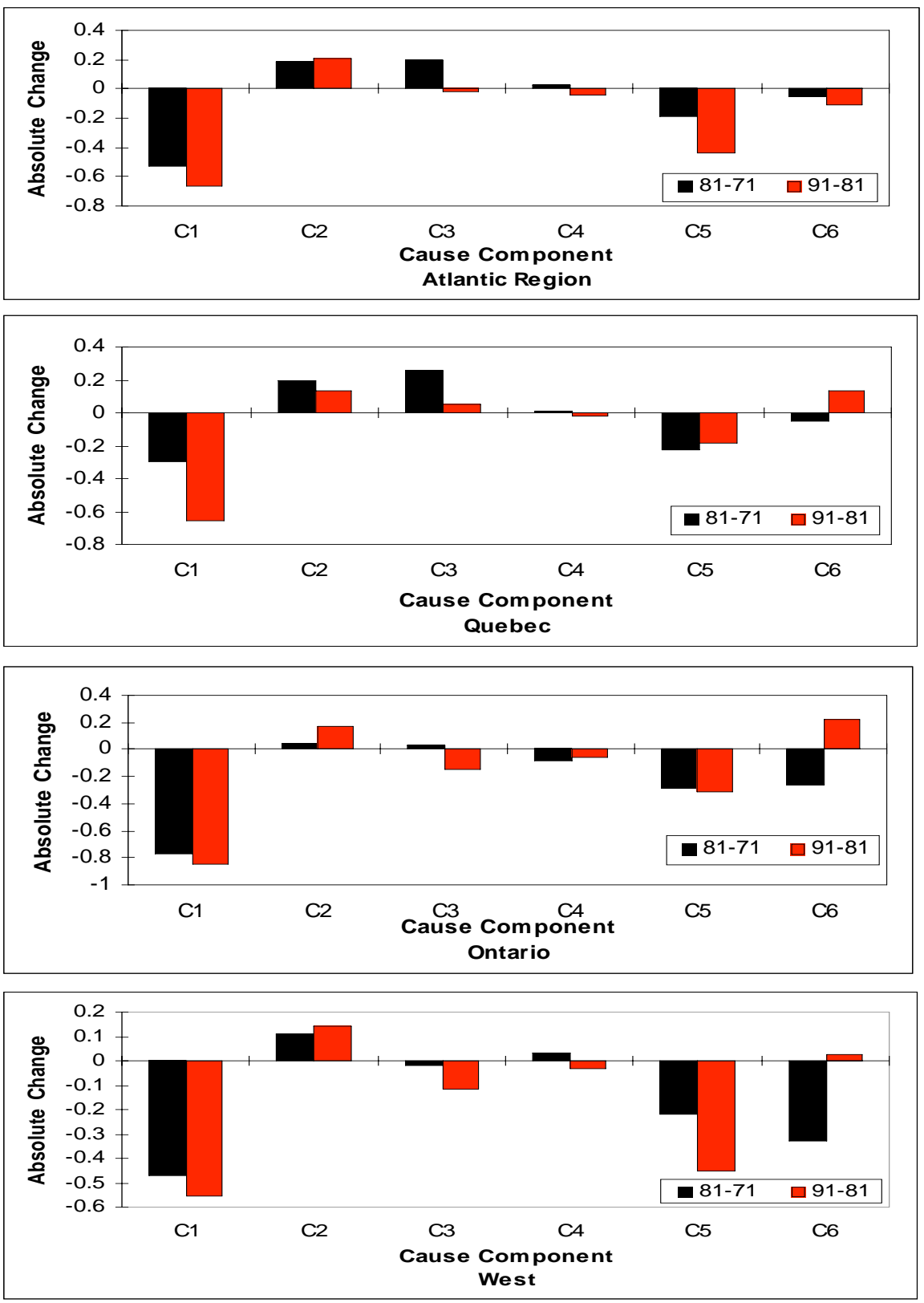

Note: $\mathrm{C} 1=$ Heart Disease $; \mathrm{C} 2=$ Cancer excluding that of the lung; $\mathrm{C} 3=$ Lung Cancer; C4 = Other Chronic; C5 = External; C6 = Residual Causes 
contribution of this component has been getting smaller during the 1980s. This has resulted as a function of a deceleration in male risk from lung cancer mortality, in conjunction with an acceleration of female death rates from this disease (See Appendixes A and B).

The effect of change in sex differences in mortality due to "Other" cancers also continues to widen the sex difference in expectation of life in all four regions. However, unlike in the Atlantic, Ontario and the West, Quebec has witnessed a declining contribution of this component during the most recent decade. Thus, with the exception of Quebec, in the other regions male mortality from "other" cancers has been rising faster than female corresponding female death rates, therefore contributing to a widening difference in life expectancy overall.

With respect to "other chronic" disease (Cause 4), in the Atlantic, Quebec and the West regions, there occurred a transition in the 1980s, where the contribution of this cause changed from slight positive (i.e., a widening effect), to slight negative (i.e., a narrowing effect). In Ontario, the contribution of this component was already negative as early as 1971. As far as the "residual" cause is concerned, its contribution to the criterion variable is positive in the most recent interval for the cases of Quebec, Ontario and the West. In the Atlantic region it has been contributing to a narrowing of the sex gap since the 1970s, intensifying during the 1980 s.

\section{Discussion}

Since the early 1970s Canadian men and women have been experienced varying degrees of improvement in overall life expectancy. On balance, the gains have been somewhat larger for males than for females, thus accounting for small, yet significant constriction of the sex gap in overall survival. This phenomenon represents a sharp break from a historical pattern of widening discrepancies in life expectancy between the sexes that began around the turn of the $20^{\text {th }}$ century. The classical version of epidemiological transition theory (Omran, 1971) failed to anticipate this recent unexpected development, which at the threshold of the new millennium appears to be a characteristic feature of the most advanced societies of the world. From this analysis, three common trends account for a large part of the noted constrictions in regional sex gaps in life expectancy. First, over the course of the 1970s and eighties men have experienced greater sustained mortality improvements than women in heart disease mortality. They have also enjoyed larger improvements in survival probabilities concerning external types of mortality ---i.e., suicide, homicide and accidents, combined. Thirdly, male survival probabilities from lung cancer (another major cause of premature death) have gone up, while reducing for women.

These trends are largely attributable to long-term changes in male and female health behaviours that may have began several decades ago. For instance, male 
smoking prevalence rates---a major risk factor for cancer and cardiovascular complications---have been dropping since the 1960s or earlier, while those of women have been going up (Lopez, 1995; Nathanson, 1995). It has been suggested by Nathanson (1995) that the emancipation movement may have played a large role in their rising incidence of lung cancer in industrialized nations (see also Bartecchi et al., 1994; Chollat-Traquet, 1992). "What has happened," according to Lopez, Caselli and Valkonen (1995:112), "is that social and economic emancipation ... has removed societal taboos against practices such as cigarette smoking." Ruzicka (1995) has reported recent increases in female suicide and accidental mortality in some industrialized societies. He opines this is likely a function of increased stress levels in a context of rapid social change.

Notwithstanding the existence of some regional differences in the magnitude of sex gaps in life expectancy, the evidence in this analysis is not inconsistent with the proposition that, as noted by Goyder (1993), social demographic regimes of Canadian regions are following a long-term homogenizing trend. Life expectancy variability across provinces has been diminishing since the 1950s; and the sex gap in life expectancy across region has also been constricting, as indicated by the decomposition analysis and the coefficient of variation in Table 1 for the sex difference over time. At the micro level, spatial differences in the degree of life expectancy constriction between the sexes would be tied to regional differences in sex based differences in life styles, health habits and behaviors, and health care utilization. At the structural level, variations may be linked to population compositional differences across regions: sex differentials in income inequality, poverty, and employment rates, among other possible demographic differentials.

In subsequent research, the present decomposition analysis may be extended to take into account the effects of cause components within age categories. In the advanced societies most deaths take place at ages above 65 (Olshansky and Ault, 1986; Fries, 1980), suggesting that most of the sex gap in life expectancy may be a function of mortality dynamics in the older ages. While this is generally true, it is a fact that some important epidemiological trends are currently being shaped by health conditions and behaviours specific to young adults (e.g., HIV/AIDS) (Rogers and Hackenberg, 1987). Thus we surmise that a decomposition analysis of gender differences in life expectancy by region would reveal a different pattern of cause component contributions for the older and younger ages. Within younger cohorts the major contributors to sex discrepancies in overall survival would be mortality due to suicide, accidents, violence and other social pathologies. Among adults and older age components, the leading contributors would likely be chronic/degenerative ailments. Geographic location might condition such possible age effects.

In the future, further change in the sex gap in the expectation of life will depend on the pace of decline in gender-specific mortality rates from causes of death, 
particularly cancer and heart disease. In some cases a narrowing of gender difference in overall survival may occur as a function of one gender experiencing rising mortality from a given disease, while those of the other gender remain constant. In other cases, the constriction of the sex gap will materialize as a result of mortality improvements for both men and women, with one gender improving more. These possibilities should be examined systematically in future study.

\section{Acknowledgements:}

*This is a revised version of a paper presented at the Annual Meetings of the Population Association of America, Los Angeles, California, March 23-25, 2000.

This study was funded by a research grant from the Social Sciences and Humanities Research Council of Canada (No. 410-95-0844). The support of the Council is greatly appreciated. The assistance of David Odynak, Population Research Laboratory, University of Alberta, is gratefully acknowledged. We are particularly indebted to the two anonymous reviewers for this journal for their perceptive and helpful suggestions for revision.

\section{Endnotes:}

1. In comparison to Central Canada, Quebec was late in the modernization process. It was not until the late 1940s and early fifties that this province would experience rapid industrialization, intensifying during the "quiet revolution" of the 1960s. This "revolution represented more than economic transformation; it also encompassed radical shifts in value orientations in the population (see Bergeron, 1975; Krull and Trovato, 1994; Thomson, 1984; Gratton, 1992; Guindon, 1988).

2. With the rise in power of the separatist Party Quebecois in 1976 and subsequent sociopolitical changes in this society, many English speaking persons have left Quebec for other parts of Canada, with a strong directional bias toward Ontario. Due in part to these developments, since the mid-1970s Quebec has been experiencing net negative internal migration rates.

3. The life expectancies for the two territories of Yukon and Northwest Territories are not included in Table 1. Except for recent years, historical data for these two areas of Canada are not available. Expectation of life at birth values for Yukon and Northwest Territories combined are mentioned in a recent report by Statistics Canada (George et al., 1994: Tables 7a, 7b). The Territories have the lowest expectation of life in 
Canada. For both males and females, the difference in expectation of life at birth between the territories and other regions, and Canada as a whole, have been declining---though the gap is still significant.

4. It is recognized that temporal changes (decreases or increases) in life expectancy at birth are typically not equally attributable to all age categories in the life table (Arriaga, 1984). For example, in highly advanced nations, where spectacular mortality improvements in infancy and childhood have already been actualized, further survival gains in these age segments will not produce very large increases in life expectancy at age zero. In developing countries however, where the fight against death has not reached such a high level of success, improvements in early age mortality would raise life expectancy in infancy by a significant amount. It is also true that age groups experience different rank order of primacy in the causes responsible for death, as in the case of accidents and violence in youth and young adulthood, and chronic/degenerative conditions prevailing in the older ages. We acknowledge these important points, but postpone age-specific decomposition to a subsequent analysis.

5. By combining the two territories with Manitoba, Saskatchewan, Alberta and British Columbia, we acknowledge that because the territories have lower life expectancies than each of these provinces, aggregation would have the effect of reducing the overall life expectation of the West region by some degree.

\section{References:}

Acsadi, GY. and J. Nemeskeri. 1970. History of Human Lifespan and Mortality. Budapest: Akademiai Kiado.

Arriaga, Eduardo E. 1984. "Measuring and explaining the change in life expectancies," Demography 21 (1): 83-96.

Bartecchi, Carl F., Thomas D. MacKenzie and R.W. Schrier. 1994. "The human costs of tobacco use: Part I," The New England Journal of Medicine 330 (13): 907-912.

Belanger, Alain. 1999. Report on the Demographic Situation in Canada, 19981999. Current Demographic Analysis. Ottawa: Minister of Industry (Catalogue No. 91-209-XPE).

Bergeron, Leandre. 1975. The History of Quebec: A Patriot's Handbook. Toronto: NC Press. 
Chollat-Traquet, Claire. 1992. Women and Tobacco. Geneva: World Health Organization.

Das Gupta, Prithwis. 1993. Standardization and Decomposition of Rates: A User's Manual. U. S. Department of Commerce. (Cat. No. P23-186). Washington, DC.

George, M. V., M. J. Norris, F. Nault, S. Loh and S.Y. Dai. 1994. Population Projections for Canada, Provinces and Territories, 1993-2016 (Tables 7a and 7b). Ottawa: Statistics Canada, Demography Division, Population Projection: Minister of Industry, Science and Technology (Cat. No. 91-520).

Goyder, John. 1993. "The Canadian syndrome of regional polarities: An obituary," Canadian Review of Sociology and Anthropology 30 (1): 112 .

Guindon, Hubert. 1988. Quebec Society: Tradition, Modernity, and Nationhood. Edited by Roberta M. Hamilton and John L. McMullan. Toronto: University of Toronto Press.

Hiller, Harry H. 1986. Canadian Society: A Macro Analysis. Scarborough: Prentice Hall Canada.

Henripin, Jacques. 1954. La Population Canadienne au debut de XVIIIe Siecle. Paris: Institut National de Etudes Demograhiques.

Innis, Harrold, 1930. The Fur Trade in Canada: An Introduction to Canadian Economic History. New Haven: Yale University Press.

Krull, Catherine and Frank Trovato. 1994. "The Quiet Revolution and the sex differential in Quebec suicide rates: 1931-1986," Social Forces 72 (4): 1121-1148.

Lopez, Alan D. 1995. "The lung cancer epidemic in developed countries." Pp. 111-134 in Lopez, Alan D., Graziella Caselli and T. Valkonen (Eds.), Adult Mortality in Developed Countries: From Description to Explanation. Oxford: Clarendon Press.

Lopez, Alan D. 1983. "The sex mortality differential in developed countries." Pp. 53-120 in Alan D. Lopez and Lado T. Ruzicka (Eds.), Sex Differentials in Mortality: Trends, Determinants and Consequences. Canberra, Australia: Department of Demography, Australian National University Printing Press. 
McVey, Wayne Jr. and Warren E. Kalbach. 1995. Canadian Population. Toronto: Nelson Canada.

Manuel, D. G. and J. Hockin. 2000. "Recent trends in provincial life expectancy," Canadian Journal of Public Health 91 (2): 118-119.

Nault, Francois. 1997. "Narrowing mortality gaps, 1978 to 1995." Health Reports (Summer) 9 (1): 35-41.

Nagnur, Dhruva. 1986. Longevity and Historical Life Tables 1921-1981 (Abridged), Canada and the Provinces. Ottawa: Minister of Supply and Services (Cat. No. 89-506).

Nathanson, Constance A. 1995. "The position of women and mortality in developed countries," in Alan D. Lopez, Gabriella Caselli and Tapani Valkonen (Eds.), Adult Mortality in Developed Countries: From Description to Explanation. Oxford: Clarendon Press. Pp. 135-157.

Olshansky, S. J. and A. B. Ault. 1986. "The fourth stage of epidemiologic transition: The age of delayed degenerative diseases," The Milbank Quarterly 46 (3): 355-391.

Omran Abdel R. 1971. "The epidemiological transition: A theory of epidemiology of population change," Milbank Memorial Fund Quarterly 49: 509-538.

Preston, Samuel H. 1976. "Causes of death responsible for variation in sex mortality differentials." Chapter 6 in his Mortality Patterns in National Populations. New York: Academic Press.

Rogers, Richard G. and Robert Hackenberg. 1987. "Extending epidemiologic transition theory: A new stage," Social Biology 34 (3-4): 234-243.

Ruzicka, Lado. 1995. "Suicide mortality in developed countries." in Alan D. Lopez, Gabriella Caselli and Tapani Valkonen (Eds.), Adult Mortality in Developed Countries: From Description to Explanation. Oxford: Clarendon Press. Pp. 83-110.

Statistics Canada. 1995. Life Tables, Canada and Provinces, 1990-1992. Ottawa: Minister of Industry (Cat. No. 84-537).

Statistics Canada. 1989. Life Tables, Canada and Provinces, 1985-1987. Ottawa: (Cat. No. 84-352).

Stolnitz, George. 1956. "A Century of international mortality trends: II," Population Studies 10 (1): 17-42. 
Stone, Leroy O. 1967. Urban Development in Canada. 1961 Census Monograph. Ottawa: Dominion Bureau of Statistics.

Thomson, Dale C. 1984. Jean Lesage and the Quiet Revolution. Toronto: Macmillan of Canada.

Trovato, Frank and N. M. Lalu. 1998. "The contribution of cause-specific mortality in changing sex differences in life expectancy: Seven nations case study," Social Biology 45 (1-2): 1-20.

Trovato, Frank and N. M. Lalu. 1997. "Changing sex differences in life expectancy in Australia between 1971 and 1991," Journal of the Australian Population Association 14 (2): 187-200.

Trovato, Frank and N. M. Lalu. 1996a. "Narrowing sex differences in life expectancy in the industrialized world: Early 1970 s to early 1990s," Social Biology 43 (1-2): 20-37.

Trovato, Frank and N. M. Lalu. 1996b. "Causes of death responsible for the changing sex differential in life expectancy between 1970 and 1990 in thirty industrialized nations," Canadian Studies in Population 23 (2): $99-126$.

Trovato, Frank and N. M. Lalu. 1995. "The narrowing sex differential in mortality in Canada since 1971," Canadian Studies in Population 22 (2): $145-167$.

Vallin, Jacques. 1993. "Social change and mortality decline: Women's advantage achieved or regained?" in Nora Federici, Karen Oppenheim Mason and S. Sogner (Eds.), Women's Position and Demographic Change. Oxford: Clarendon Press. Pp. 190-212.

Waldron, Ingrid. 1993. "Recent trends in sex mortality ratios for adults in developed countries," Social Science and Medicine 36 (4): 451- 462.

Manuscript Received July 2000; Manuscript Revised April 2001 
Narrowing Sex Differences in Life Expectancy

Regional Variations, 1971-1991

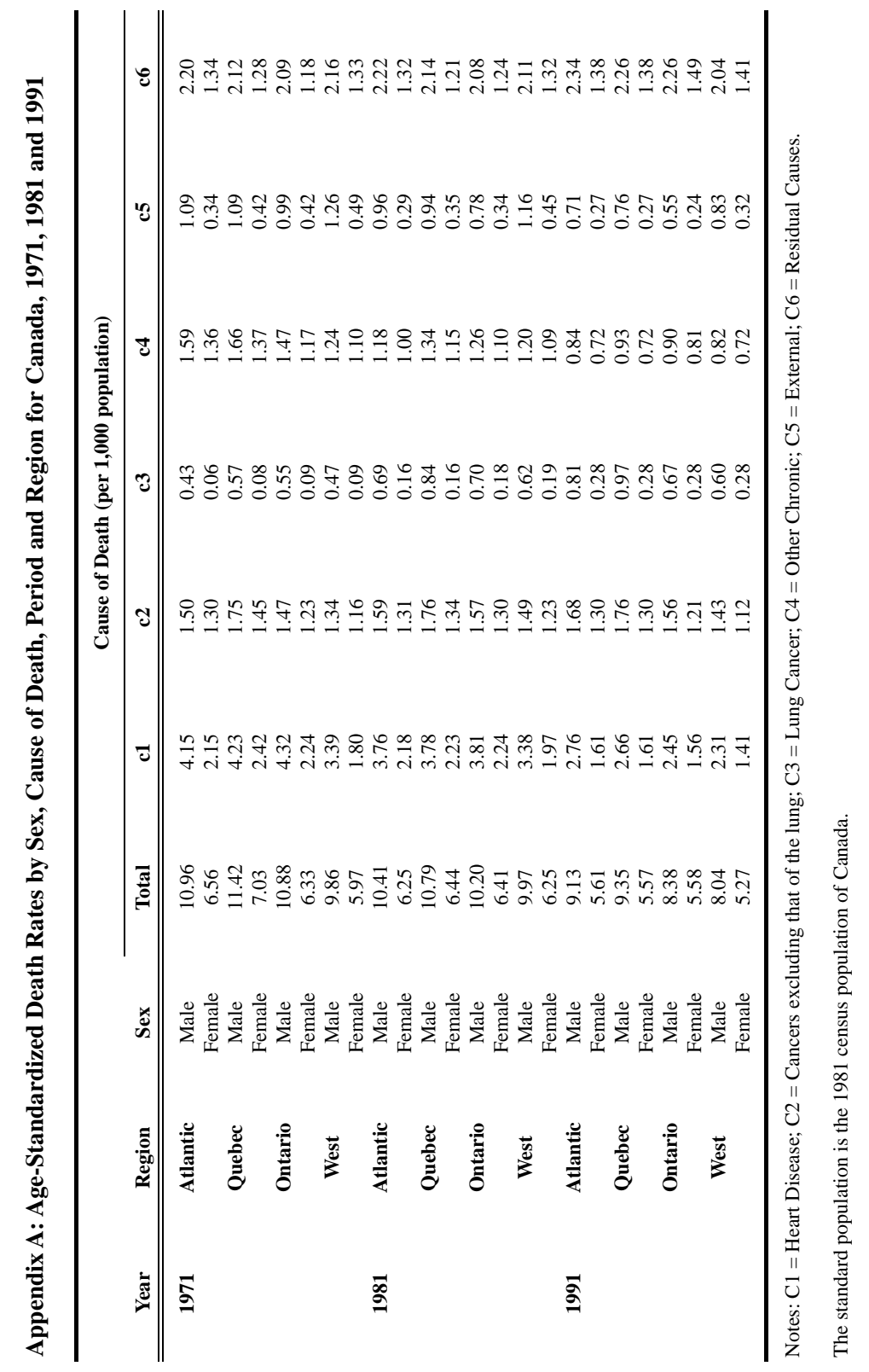




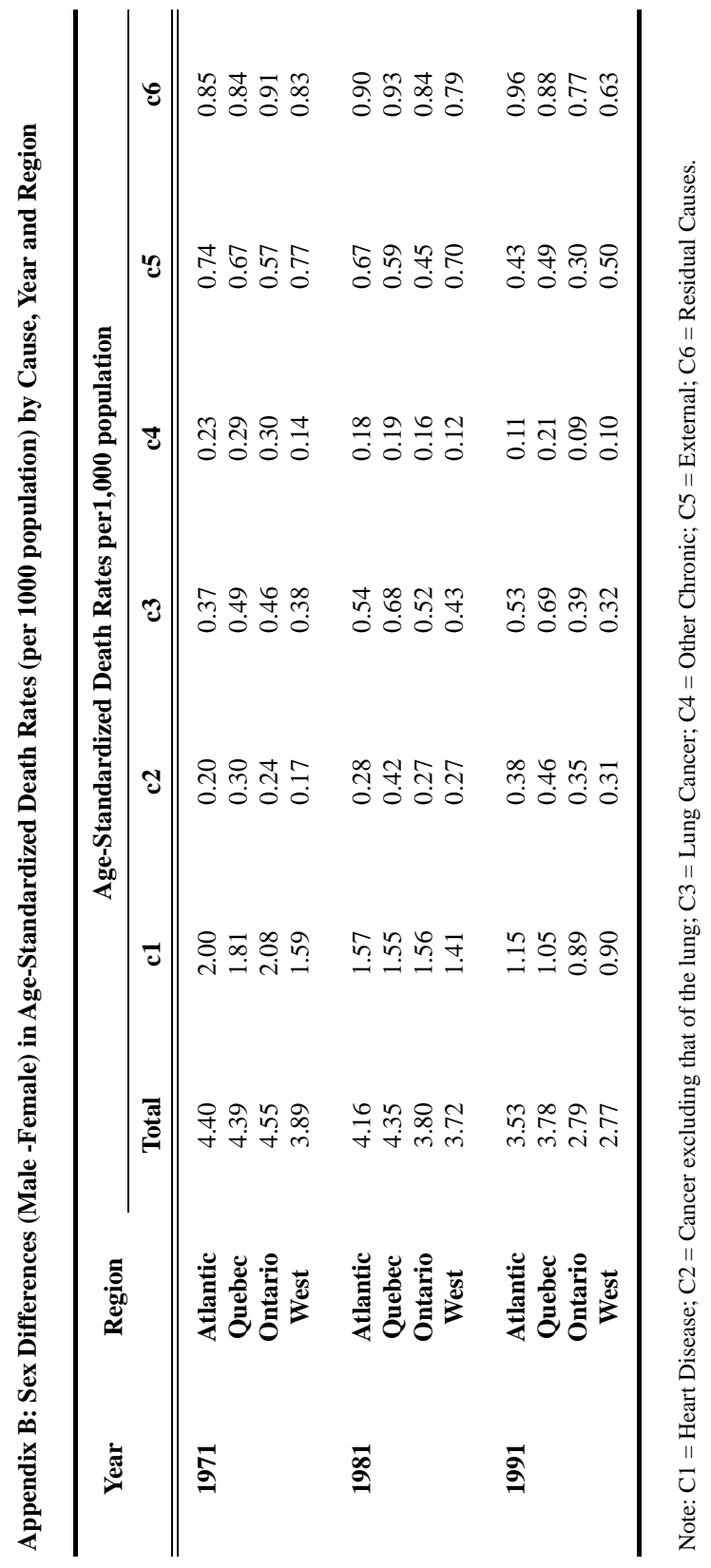

